\title{
The HR Function of the 21st Century: A Critical Evaluation of its Contributions, Strengths and where it needs to Develop
}

\author{
Kelechi John Ekuma \\ Institute for Development Policy and Management \\ School of Environment, Education and Development, \\ The University of Manchester, United Kingdom
}

\begin{abstract}
There is a broad consensus among scholars and practitioners alike that maximising the potentials of human resources is central to organisational effectiveness and performance in the 21st Century global market place of intense social Darwinism. It has indeed been suggested that the way in which an organisation manages people can influence its performance. However, the relationship between effective Human Resource Management (HRM) function and organisational performance has remained a vexed issue among scholars, managers and even among HR practitioners. Indeed, there is an ongoing debate on what the HR function really contributes to organisations. The most fundamental issue remains how to understand how HRM practices impact on performance. Consequently, producing an unequivocal response to the question 'what does HRM really contribute to organisational performance?' has remained elusive.This article critically evaluates the contemporary HR function, with a view of highlighting its contributions to organisational effectiveness and performance. It argues that there are empirical evidences to suggest that there are clear linkages between effective HR function and organisational effectiveness and improved performance, but the greatest challenge remains how to quantify these contributions. The paper also contends that a lot can still be done to maximise these linkages and contributions.It concludes that for HRto maximise its contributions, it must critically re-examine its functions and re-position itself to play a more strategic role in strengthening organisational capabilities and competencies, whileat the same time be proactive in its approach.
\end{abstract}

Keywords:HR function, Organisational Effectiveness, Employee Advocate, Functional Expert, Change Agent, Strategic Partner.

\section{INTRODUCTION}

The cliché 'people are our greatest assets' and the fact that employees are the critical element in a firm's success have become common wisdom (Hall, 2005). There is a broad agreement among scholars and practitioners alike that maximising the potentials of human resources is central to organisational effectiveness and performance in the 21st Century global market place of intense competition. Indeed, the management of human capital in organisations has become a central factor in maintaining and improving organisational performance (Lambooij et al., 2006; Crawshaw Budhwar \& Davies, 2014). 
Given the above, there is therefore, the critical need to maximally harness the potentials of employees through effective HR interventions by appropriately aligning the overall business strategy with the HR strategy for maximum productivity. As Delaney and Huselid (1996) argue, the way in which an organisation manages people can influence its performance.

Despite this realisation however, the relationship between effective Human Resource Management (HRM) function and organisational performance has remained a vexed issue among scholars, managers and even among HR practitioners. While some commentators (e.g. Delaney \& Huselid, 1996; Abella, 2004) argue that effective HR practices remain the kernel for achieving competitive advantage, others (e.g. Guest, 1997,1998) are sceptical of this claim and question the basis of linking HR practices to organisational performance. An assessment of recent literature on the subject matter, indicate that the controversy still rages.

It is against this backdrop and in recognition of the costs (both implicit and direct) associated with the HR function, that this paper critically evaluates the HR function, with a view of highlighting its contributions to organisational effectiveness and performance. It argues that there are empirical evidences (e.g. Hyde et al, 2006; Katou \& Budhwar, 2010; Hertog et al, 2010; etc) to suggest that there are clear linkages between effective HR function and organisational effectiveness and improved performance, but the greatest challenge remains how to quantify these contributions. The paper also notes that a lot can still be done to maximise these linkages and contributions; and while not pretending to have any 'best practice' paradigm, it concludes that for this to happen (i.e maximising HR's contributions), HR must critically re-examine its functions and position itself to play a more strategic role in strengthening organisational capabilities and competencies and be proactive in its approach (Abella, 2004; Thomas \& Lazarova, 2014).

\section{The HR Function: A Critical Assessment}

There is no consensus among scholars and practitioners alike on what precisely constitutes the HR function, neither are there any univocal definitions. However, there is a general agreement that it is a critical business function. At its most basic level, the HR function comprises all the roles and activities performed by $\mathrm{HR}$ in organisations towards achieving organisational strategic objectives. Building organisational capability is HR's heartland (Holbeche, 2009; Crawshaw et al, 2014).

A critical assessment of the HR function, clearly indicate that it has evolved continuously over the years. Traditionally, it was largely administrative in nature, comprising what is now seen as transactional aspects of HR, such as recruitment and selection, induction of new staffs and maintaining of staff records (Markington \& Wilkinson, 2008; Thomas \& Lazarova, 2014). Foot and Hook (2002: 3) identify these transactional HR function to include:

- Recruitment and selection: concerned with the

- Training and development

- Human resource planning

- Provision of contracts

- Provision of fair treatment

- Provision of equal opportunities

- Assessing performance of employees

- Employee counselling

- Employee welfare

- Payment and reward of employees

- Health and safety 
- Discipline and dealing with grievances

- Dismissal and Redundancy.

However, the increasing global nature of competition requires that firms maximally utilize all their available resources (finance, marketing, HR etc.) as a means of achieving a competitive advantage (Wright et al, 1998). Subsequently, there was great emphasis on the alignment of all functional activities of the firm, including HR toward achievement of strategic objectives. The HR function was therefore, expected to support the organisation in achieving high performance people management and managing the changes required to improve efficiency, even as many advocated a more strategic role for the function (Wright et al, 1998; Abella, 2004).

In the same vein, changes in the nature of managerial work over the years, coupled with new models of organisational flexibility, technological developments and the changing world of work, means that the contemporary HR function is remarkably different from what it was two or three decades ago. As Caldwell (2003: 984) rightly argues, 'the emergence of HRM as a panacea for integrating business strategy and people management has exposed personnel practitioners to a new set of role demands, professional challenges and management expectations; even as there have become greater involvement of line mangers. The CIPD (2006: 6) aptly sums the situation thus:

The HR function has changed substantially from our original understanding of what an HR function should look like, with increased segmentation, devolution and outsourcing of departments. The HR function is transforming its focus from the management of human resources to the development and maintenance of organisational effectiveness.

Several works have attempted to capture this new set of demands, and the changing HR function. Marching ton \& Wilkinson (2008: 179), for instance, summarizes the 'new' $H R$ functions to include: administration, negotiation, legal expertise, organisational development and business partner. Similarly, Storey (1992) has long ago identified what Caldwell (2003: 987) refers to as the fourfold typologies of HR function based on the basis of two bi-polar dimensions: intervention versus non-intervention and strategy versus tactics. These roles are: advisors, service provider, regulators and change makers. See Table

Table 1: The Fourfold Typologies of HR function

- Service Provider: provides line managers specific HR assistance and support as required. Handmaidens.

- Regulator: formulates, promulgates and monitors the observance of HR policy and practice.

- Change makers: actively pushes forward processes of culture change and organisational transformation.

Source: Caldwell (2003).

However, the Ulrich's (1998) model, perhaps, provides the most succinct systematic frameworks for capturing the contemporary HR function. Ulrich (1998) cited by Caldwell (2003, p. 986) insists that HR professionals must overcome the traditional marginality of the personnel function by embracing a new set of roles as champions of competitiveness in delivering value; and identifies the following as the 'contemporary' HR function: employee advocate, functional expert, human capital developer, strategic partner and HR leader (CIPD, 2006). See fig 


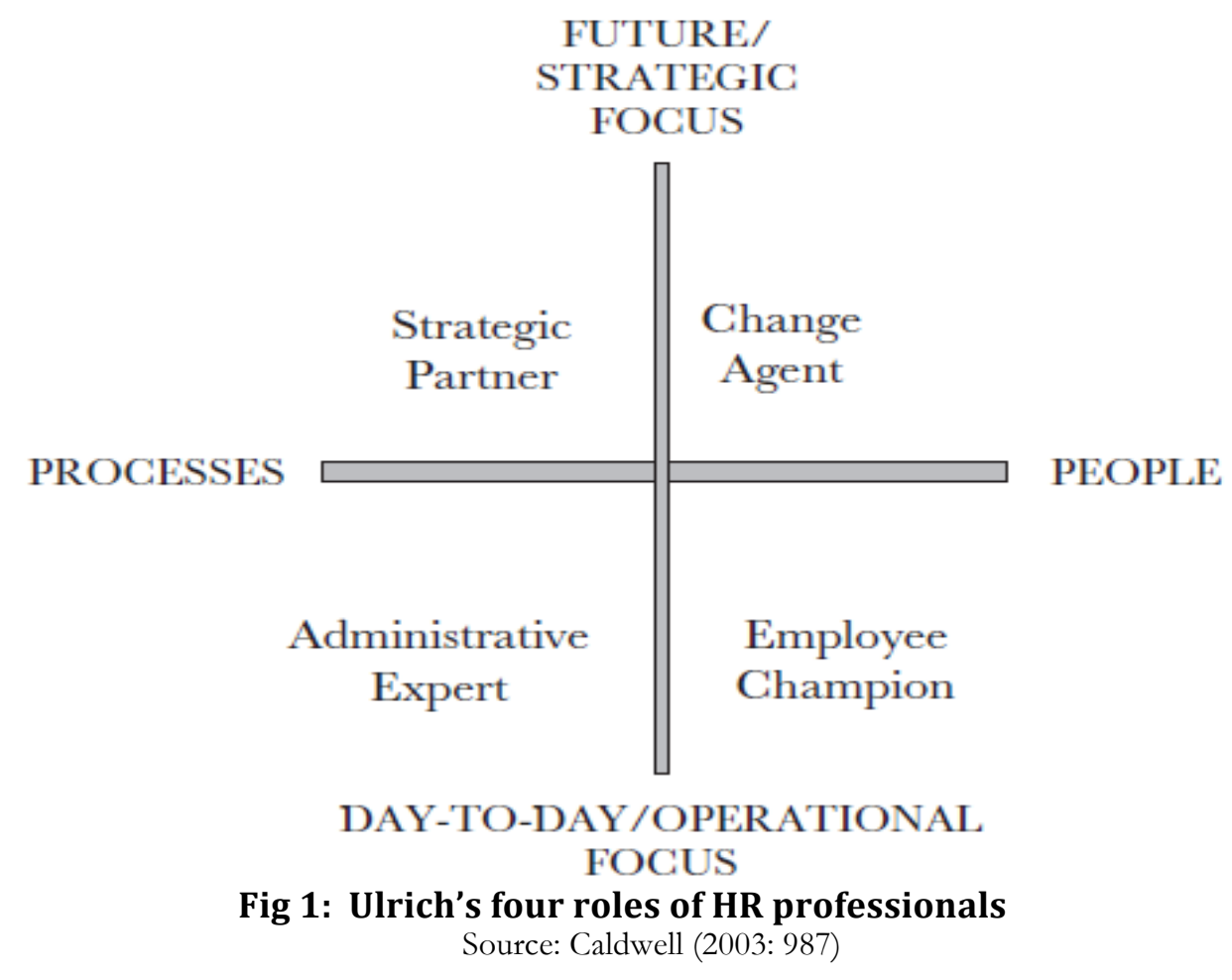

An expansion of the responsibilities associated with the above HR roles, clearly reveal the contributions of the HR function to organisational effectiveness and performance. Using the Ulrich model as a guide, the next few paragraphs critically analyses these HR roles and its functions with the aim of highlighting and quantifying its contributions to organisational performance. It is instructive to point however, that despite its limitations, the Ulrich model has been adopted to ensure lucidity.

\section{CONTRIBUTIONS OF THE HR FUNCTION TO ORGANIZATIONAL EFFECTIVENESS AND PERFORMANCE: A CRITICAL OVERVIEW}

As already noted, there is a continuing debate on what the HR function really contributes to organisations. The most fundamental issue remains how to understand how HRM practices impact on performance (Hall, 2004; Thomas \& Lazarova, 2014). Consequently, producing an unequivocal response to the question 'what does HRM really contribute to organisational performance?' has remained elusive (Guest, 1987, cited in Tyson, 1998). Indeed, many (e.g. Hall, 2005) have questioned the usefulness of HR to organisations.

The plethora of criticisms against the HR function includes what some analysts have characterised as the lack of business awareness, lack of practical relevance of most of its policies and obsession with rules (Hall, 2005; Lee, 2003). Perhaps, this is why some critical scholars (e.g. Banjoko, 2007; McGuire, 2014), argue thatmost of the HR function is nothing but a fad. Indeed, the function has also been criticised for adding costs, instead of value to the organisation, because it does not really prove its contributions in financial terms and returns on investment. It is this line of reasoning that led Banjoko (2007) to conclude that what organisations need are not effective HR departments, but effective line managers, arguing that delivering organisational reality and objectives is the responsibility of line managers and executives, and not HR.

However, a critical assessment of the function seems to suggest otherwise and indicates that it indeed, adds value and contributes to organisational performance in no small way. In specific 
terms and adapting the Ulrich model as a guide, the HR function makes the following contributions to organisational effectiveness:

\section{Employee Advocate}

As an employee advocate, the HR function maximises employee commitment and contribution (Caldwell, 2003). It does this by acting as a voice for employees both in representing their concerns to senior managers, empathising with them, and in working to improve their contributions, commitment and engagement (Marchington \& Wilkinson, 2008: 187). As a result, employees are highly motivated and committed to organisational objectives, which in turn translate to low staff turnover, efficient work force and increased productivity.

Tsui et al. (1997), have since corroborated this view, when they argue that an employer that takes care of its employee is most likely to get the best out of them. Relying on the Mutualinvestment model, they affirm that when employer looks after her employees, her employees will look after her. When an employer signals that she takes care of the well-being of her employees, employees will react with more good will, commitment and willingness to corporate (Lamboij et al, 2006; Crawshaw et al., 2014).

\section{Functional Expert}

In fulfilling this role, HR constantly improves organisational efficiency by re-engineering the HR function and other work processes (Caldwell, 2003: 987). As Marchington and Wilkinson (2008: 187) point out, 'HR is a profession that possess a body of knowledge about the management and development of people which can assist both them and the organisation to make effective decisions'. This is especially true in today's global economy where all that matters is 'knowledge'. In this capacity, the HR function contributes to 'foundational' practises such as recruitment and selection, promotions and rewards/remuneration, as well as to other areas of business operations such as work process design, organisational structures, internal communication, salary administration, employee records, redundancies and so on (Marchington \& Wilkinson, 2008). Undoubtedly, without these functions, no organisation will survive. Perhaps, it is the meticulous way in which HR handles these functions that some analysts have characterised as obsession with rules.

\section{Human Capital Developer and 'Change Agents'}

The HR function also contributes in delivering organisational transformation and culture change (Caldwell, 2003; Crawshaw et al., 2014). As a human capital developer and 'change agents', the function fulfils this responsibility by actively building and maintaining a corporate culture that embraces people development (Abella, 2004: 39). In line with the concept of Human Capital Theory (Becker, 1964) and the Resource Based View of organisations (Barney \& Wright, 1998), an organisation that constantly updates the skills, knowledge and competencies of its workforce (the learning organisation) through an effective HR driven learning and development strategy, will definitely have a sustainable advantage over its competitors. Devanna (1984) supports this argument, when he affirms that HRM and highly skilled employees are now often seen as major factors differencing between successful and unsuccessful organisation, more important than technology or finance in achieving a competitive advantage.

\section{Strategic Business Partners}

What is more, the HR function equally contributes to the formulation and effective implementation of business strategies. As 'strategic/business partners', it has shown itself capable of playing a critically central role in the successful formulation and execution of 
business strategies and in meeting customers' needs (Caldwell, 2003). As Marchington and Wilkinson (2008: 188) observe, by being actively involved in crafting strategies that help to align customer needs and organisational approaches; and 'leading on how to raise the standards of strategic thinking for the management team, the HR function plays a significant part in creating the systems and processes that help deliver organisational success'.

From the forgoing analyses, it is evident that the contributions of the HR function to organisational performance are wide-ranging and indeed, critical. This is most evident in its capacity to:

- Motivate and engage employees for maximum commitment and productivity.

- Recruit and develop highly skilled and competent workforce to deliver business objectives.

- Deliver appropriate reward strategies to match employee contributions and enhance performance.

- Engage in functional and technical roles such as redundancy handling and grievance/disciplinary procedures with subsequent cost savings for organisations.

- Partner with senior managers to formulate and implement appropriate strategies to achieve business objectives.

The forgoing reflects the characteristics of the high commitment HR approach (see: Thomas \& Lazarova, 2014). Therefore, it is plausible to argue that organisational performance is centrally hinged on the effectiveness of the HR function, particularly the high commitment model. Corroborating this assertion, Devana (1984: 41) argues that:

Performance is a function of all the HR components: selecting people who are the best able to perform the jobs defined by the structure; appraising their performance to facilitate the equitable distribution of rewards; motivating employees by linking reward to high level of performance; and developing employees to enhance their current performance at work as well as to prepare them to perform in positions they may hold in the future. Fig 2, gives a simple graphic representation of the HRperformance link.

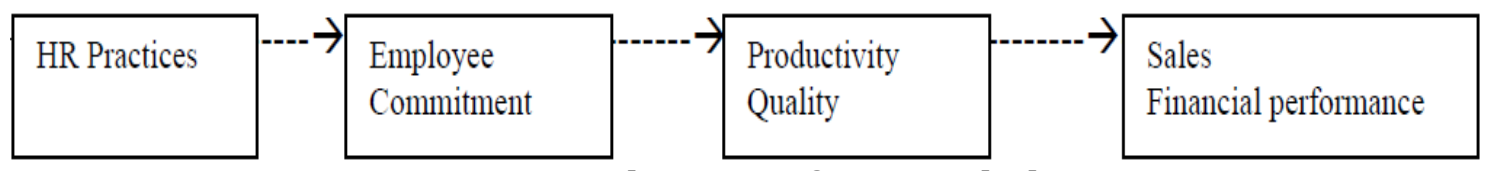

Figure 2: The HR-performance link

Source: Adapted from Guest (2007).

Yet, it must be admitted that line managers are indeed, very critical to organisational performance. Delivering the reality should therefore, be a shared task between HR and line managers and executives. As Holbeche (2009) rightly pointed out:

It is line managers who are key communication gateways, whose priorities influence how people spend their time, whose management styles have a direct bearing on the climate for performance. It is managers, executives and leaders at all levels who model values, provide clarity of direction, create employee engagement and change-ability.

\section{CONCLUSION}

It is evident from the analysis in this article, that the HR function is very crucial to organisational survival and gaining of competitive advantage. Although with several daunting 
challenges, especially the inability of the HR function to quantify its contributions in monetary terms and ROI, the function nonetheless remains central in maintaining the psychological contract and affects the knowledge, skills, abilities, attitudes and behaviours of employees (Thomas \& Lazarova, 2014). HR also continuously contributes to effective strategy formulation and implementation, thus, making the function fundamental to organisational performance and competitiveness (Crawshaw et al., 2014).

It must be acknowledged however, that despite these sterling contributions, the HR function still needs to improve in certain areas, so as to position itself to make more well-informed strategic contributions to organisational success in line with changing demands and exigencies of the business environment. As more and more is expected of employees, the HR function must be more than an administrative arm of an organisation and be increasingly involved in facilitating growth, productivity and profitability (Abella, 2006: 37).

\section{Recommendations and Implications for HR}

Given the above, the HR function, must therefore, become more strategic and proactive in its approach and tailor its contributions to support the realisation of the strategic business objectives. One major way of achieving this, is through the Strategic Business Partner approach and effective workforce planning (CIPD, 2009). As noted earlier, one of the greatest criticism always levelled against the HR function, is that of lack of alignment and proper integration with the overall business strategy. While this argument is not totally valid or totally false, there is nonetheless, the need to properly align HRM with organisational strategy (strategicfit/vertical integration), and the alignment of various HR functions such as career opportunities, training, appraisal and so on, with the organisation (internal fit/horizontal integration) (Baron \& Kreps, 1999; Crawshaw et al., 2014).

Similarly, apart from striving to achieve strategic and internal fit, and supporting the organisation in achieving high performance people management, as well as managing the changes required to improve organisational efficiency, the HR function needs to review its own performance to ensure that it is efficient and effective (EO, 2007). This kind of re-assessment is crucial if the HR function is to continue delivering quality service, attain a return on investment (ROI) and further prove its contributions (Abella, 2004). In this regard, emphasis should be on whether:

- The function's service plan (i.e. HR strategy) reflects organisational need and appropriate strategy for the deployment, management and development of the workforce is in place. Simply put, do we have the appropriate HR strategy?

- There is appropriate HR leadership so that people issues are considered at the outset of any organisational change.

- The current HR function organisational structure and the HR job roles reflect and meet service needs.

- The processes and systems used ensure that administrative and reporting tasks are delivered in a timely and efficient manner.

- There is an effective interface between the HR function and managers, employees. Trade unions and potential employees and all parties are clear about their roles and responsibilities in relation to the service provided.

- HR staff have the relevant competencies and capabilities to deliver what is required

- Performance is appropriately managed and service delivery changes are made in a timely manner; even as there should be a clear strategy for evaluating the above (EO, 2007: 1). 
This review should be systematic and evaluative, and can be done independently by the HR function or in a wider organisational context by critically auditing the current system and job roles, benchmarking against other HR functions and consultations with key stakeholders, including line managers, employees, trade unions and HR staff (EO, 2007: 1).

In addition, there is also the need to properly address certain strategic HR issues such as: the responsibility of the HR function, responsibility of line managers with regards to HR issues and technological requirements to support the growing responsibilities of the HR function in a rapidly changing world (Thomas \& Lazarova, 2014; CIPD, 2007). As Abella (2004: 38) succinctly puts it:

In order for the HR function to move from the backroom to the boardroom, HR issues must be addressed, and the role of line managers must evolve into that which accommodates an increasing involvement in developing solutions to address the concerns of their people.

Undoubtedly, the foregoing will re-engineer the HR function and make it a more strategic contributor, greatly improve services, lead to increased business focus and profoundly reduce costs (CIP, 2007).Given the attendant benefits of the strategic business partner approach, it is plausible to argue that maximising the strategic contributions of the HR function and the need to become strategic business partners should be a primary pursuit of HR practitioners. While this is desirable, the recognition that less strategic and administrative functions of HR are nonetheless critical for organisational success, means that emphasises should also be on how to improve the efficacy and utility of these non-strategic and 'traditional' functions as well. The challenge therefore, is how to strike a balance between developing an effective HR strategy and policies; and contributing to business strategy on one hand, and providing support to line managers and HR administrators on the other. The implication therefore, is for the HR function to be both transactional and transformational (CIPD, 2007; Crawshaw et al., 2014).

\section{References}

[1]. Abella, V.O., The HR function of the future. The SGV Review, 2004. (March): p. 36-41.

[2]. Banjoko, S. A., Human resource management: An expository approach, 2007. Ibadan: Oluseyi Press.

[3]. Barney, J., Firm resources and sustained competitive advantage. Journal of Management, 1991. 17(1): p. 99120.http://dx.doi.org/10.1177/014920639101700108 [Accessed 11November 2014].

[4]. Becker, B. and Gerhart, B., The impact of human resource management on organisational performance: progress and prospects. The Academy of Management Journal, 1996. 39(4). http://dx.doi.org/10.2307/256712 [Accessed 11 November 2014].

[5]. Becker, G. S., Human Capital: A theoretical and empirical analysis, with special reference to education, 1964. Chicago, University of Chicago Press (United Sates).

[6]. Caldwell, R., The changing roles of personnel mangers: Old ambiguities, new uncertainties. Journal of Management Studies, 2003. 40(4) (June): p.983-1011.http://dx.doi.org/10.1111/1467-6486.00367 [Accessed 14 November 2014].

[7]. Cooke, F.L., Human resource strategy to improve organisational performance: A route for British firms? ESRC future of work programme, Working Paper, 2000. 9 (October). 
Ejuma, K. J. (2015). The HR of the 21st century: A Critical Evaluation of its Contribution, Strengths and where it Needs to Develop. Advances in Social Sciences Research Journal, 2(1), 24-33.

[8]. Crawshaw, J.R., Budhwar, P., and Davis, A., Human resource management: Strategic and international perspectives, 2014. London: Sage.

[9]. Delaney, J.T \& Huselid, M.A.,The impact of human resource management practices on perceptions of organisational performance. Academy of Management Journal, 1996. 39(4): p. 949-968. http://dx.doi.org/10.2307/256718 [Accessed 23 November 2014].

[10]. Employer's Organisation (EO)., The people implication of the efficiency agenda: The HR function and efficiency, 2007. (Advice Booklet). London: EO.

[11]. Foot, M., \& Hook, C., Introducing human resource management, 2002. Harlow, Essex: Pearson Education

[12]. Guest, D., Human resource management and performance: A review and research agenda. The International Journal of Human Resource Management, 1997. 8(3): p. 263-276.http://dx.doi.org/10.1080/095851997341630 [Accessed 14 November 2014].

[13]. Guest, D., Beyond HRM: commitment and the contract culture, in M, Marchington \& P, Sparrow (eds.) Human resource management: the new agenda, 1998. London: Financial Times, Pitman

[14]. Hall, L., HRM practices and employee and organisational performance: a critique of the research and Guest's model, 2005. Research working paper.

[15]. Hertog, F .D, Iterson, A.V. and Christain, M., Does HRM really matter in bringing about strategic change? Comparative action research in ten European steel firms. European Management Journal, 2010. 28(1) (Feb.): p. 14 - 24.http://dx.doi.org/10.1016/j.emj.2008.11.002 [Accessed 23 November 2014]

[16]. Holbeche, L., Building high performance- The key role for HR. Impact, 2009. P. 20

[17]. Huselid, M.A., Jackson, S.E., and Schuler, R.S., Technical and strategic human resource management effectiveness of firm performance. Academy of Management Journal, 1997. 40(1): p. 171-188. (Online). Available at: http://www.jstor.org/stable/257025 [Accessed 13 November 2014]

[18]. Hyde, P., et al., Improving health through human resource management: Mapping the territory, 2006. London: CIPD.

[19]. Katou, A. A., and Pawan, S, B., Causal relationship between HRM policies and organisational performance: evidence from the Greek manufacturing sector. European Management Journal, 2010. 28(1):p.2529.http://dx.doi.org/10.1016/j.emj.2009.06.001 [Accessed 23 November 2014].

[20]. Lamboij, M., et al., Human resource practices and organisational performance: Can the HRM-performance linkage be explained by the cooperative behaviours of employees? The International Review of Management Studies, 2006. 17(3): p.223-240.

[21]. Marchington, M.., \& Wilkinson, A., Human resource management at work: people management and development, 2008. 4th ed. London: CIPD.

[22]. McGuire, D., Human resource development, 2nd edition, 2014. London: Sage.

[23]. The Chartered Institute of Personnel and Development (CIPD)., HR strategy: Creating the framework for people management, 2005. London: CIPD.

[24]. CIPD., The changing HR function: Survey Report, 2007. London: CIPD. 
[25]. Thomas, D.C., and Lazarova, M. B., Essentials of international human resource management: Managing people globally, 2014. London: Sage.

[26]. Tsui, A., A multiple constituency model of organizational effectiveness: An empirical examination at the human resource subunit level. Administrative Science Quarterly, 1990. 35: p.458-483.http://dx.doi.org/10.2307/2393313 [Accessed 14 November 2014]

[27]. Tyson, S., How HR knowledge contributes to organisational performance. Human Resource Management Journal, 1998. 9(3): p. 42-53. http://dx.doi.org/10.1111/j.1748-8583.1999.tb00202.x [Accessed 11 November 204].

[28]. Wright, P.M., et al., Strategy, core competence, and HR involvement as determinant of HR effectiveness and defining performance. Human Resource Management, 1998. 37 (1): p. $17-$

29.http://dx.doi.org/10.1002/(SICI)1099-050X(199821)37:1<17::AID-HRM3>3.0.CO;2-Y [Accessed 11 November 2014]. 